\title{
Towards the Adoption of Smart Manufacturing Systems: A Development Framework
}

\author{
Moamin A. Mahmoud ${ }^{1}$, Jennifer Grace ${ }^{2}$ \\ College of Computing and Informatics \\ Universiti Tenaga Nasional \\ Kajang, Malaysia
}

\begin{abstract}
Today, a new era of manufacturing innovation is introduced as Smart Manufacturing Systems (SMS) or Industry 4.0. Many studies have discussed the different characteristics and technologies associated with SMS, however, little attention has been devoted to study the development process when establishing new SMS. The study's objective is to propose a development framework that increases the adoption and awareness of Industry 4.0 among manufacturers and aids decision-makers in designing better SMS capabilities. The framework consists of three phases, iterative process of application modelling; evaluation to ensure optimal configuration and adoption; and finally implementation. The proposed framework is hoped to assist the industries' management in planning for the adoption of technology, in establishing SMS or assessing the need in existing ones. Indirectly, more industry will gain the benefits as a support for their initiatives to transform into Industry 4.0.
\end{abstract}

Keywords-Component; smart manufacturing; industry 4.0; development framework; simulation-based evaluation

\section{INTRODUCTION}

Smart Manufacturing Systems (SMS) refers to communication and computing technologies that enable all manufacturing system's components to be digitally connected and data analytics-driven, thus achieving intelligent coordination. It comes with several significant benefits such as cost reduction, higher productivity, resources efficiency, product customization, and minimizes negative environmental impacts.

The increasing demand of digitally connected machines and knowledge-based manufacturing systems indicates the continuing and rapid growth of SMS [1]. government investments by industrialized nations and developing countries in smart manufacturing adoption that significantly increased for the last few years contributes the growth of SMS. [2]. However, the adoption and awareness of Industry 4.0 among manufacturers in Malaysia is still low compared to other developing countries.

According to IM BizWatch [3], 70-80\% of Malaysian industries are still wedged in the second industrial era while a majority of the neighboring countries and beyond are already building the bridge from Industry 3.0 to 4.0 [3]. Malaysian Investment Development Authority (MIDA) has reported that Malaysia is working hard to transition the industry bodies towards the adoption of automation and smart manufacturing concepts and technologies as this sector contributes almost $80 \%$ to the GDP [4]. The Ministry of International Trade and
Industry (MITI) strategizes and plans to move forward in the adoption of smart manufacturing and Industry 4.0 in Malaysia [4]. Thus, new and innovative methods are crucially needed to adopt SMS for the nation and convince industry players to invest in this sector.

Many studies have discussed the different characteristics and technologies associated with SMS [5]-[17]; however, little attention has been devoted to study the development process challenges when establishing new SMS [18]-[20] that requires pre-implementation planning and assessment leading to minimized operational cost and time, as well as efficient machine's utilization. The first main component of the process is system configuration. System configuration involves identifying required machines, their quantities, and the workflow between machines [19], as well as the required technologies such as IoT, Big Data, Cloud computing, and AI techniques. Good configurations contribute towards the overall success of SMS projects, while poor configurations may cause late or over budgeted projects as configuration is the first phase in establishing SMS and any defects will result in failure that requires re-work in all phases.

Two different models of SMS configuration have been identified from the literature: queuing model and multi-criteria decision making model [36]-[40], [53], [54]. The queuing model enables manufacturer to evaluate the throughput, work in process, and lead times. While multi-criteria decision making models is used to determine the configuration of the SMS. However, these two models are not sufficient to solve the configuration problems due to an absence of an integrated framework that can consider different scenarios based on the market demand [19] [26]. The integrated frameworks could include other AI techniques such as agent-based modeling and simulation [56]-[58] where agents are designed to handle each resource autonomously [45], [46], [53], [55], [60], which offer flexibility for each resource to collaborate/coordinate/negotiate with each other to achieve the desired goal efficiently [47], [48], [51], [52].

Modelling and simulation study plays an important role in the selection of a particular configuration and system evaluation prior implementation [21]-[23], [49], [50]. To ensure the efficient achievement of Smart Manufacturing realization, Mittal et al. [21] includes a simulation in their action roadmap. According to SME Corp Malaysia [23], of which the first and main pillar is the simulation part that constitute the nine pillars of SMS. Therefore, a simulation tool can assist in specifying the right configuration of a particular 
SMS project [19]. A Simulation is useful when the phenomenon to be studied is not directly accessible or is difficult to observe directly [24]. The idea of experimenting on models rather on the real system is not something new. For example, when an architect plans to investigate the behavior of a wind tunnel on a tower block model, they experiment on the model since the cost of experiment on a real tower block is too excessive. Thus, experimenting with simulation models as one way to obtain results and deriving the behavior of a model analytically is usually paramount because it provides information about how the model behaves given a range of inputs [25].

Therefore, in this study, we propose a development framework that increases the adoption and awareness of Industry 4.0 among manufacturers and aids decision-makers in designing better SMS capabilities. The framework consists of three phases, iterative process of application modelling; evaluation to ensure optimal configuration and adoption; and finally implementation. The rest of the paper is organized as follows: Section 2 reviews the related work on Smart Manufacturing Systems. In Section 3, we present the development framework with the three phases, Smart Manufacturing System Integration model, Simulation-based Evaluation, and the Final Model. Section 4 concludes the paper.

\section{RELATED WORK}

Today, the market is driven by consumers' expectations in terms of better quality, lower cost, and less lead-time. The efficiency of traditional manufacturing system is not sufficient to meet customers' expectations [26]. According to Shen and Norrie [41], the conventional manufacturing operations are inefficient to fulfill the rapid changes in the market requirements. Finding better ways by manufacturers become a vital need to satisfy the market [42]. Therefore, to bridge the gap between expectations of consumers and actual productions, adoption of innovative and non-traditional processes is crucial.

Fig. 1 shows the evolution of the manufacturing system, which can be traced back to the middle of the 18th century during the industrial revolution with a steam-engine. As time progressed, during the age of electricity, the mass production system was introduced in the 19th century. The third of the Industrial Revolution happened in the 20th century, where computers and automation (flexible manufacturing system) are introduced. Finally, the forth industrial revolution or the era of Industry 4.0 is introduced and is called Smart Manufacturing System [43]. In SMS, human operations are replaced by robotics equipped with necessary algorithms and marked by a fusion of technologies.

The aim of the Smart Manufacturing System (SMS) is to share the right data to the right machine at the right time with required format [26]. Several terms are used in the literature for SMS such as an intelligent factory, a smart factory, factory of things [44]. In 2011, Germany introduced the terms of industry 4.0, which is referring to SMS. They provided a vision that emphasized on using communication technologies based on Cyber Physical System (CPS), Internet-of-Things (IoT) and IoS (Internet of Services) to resolve SMS obstacles [43].

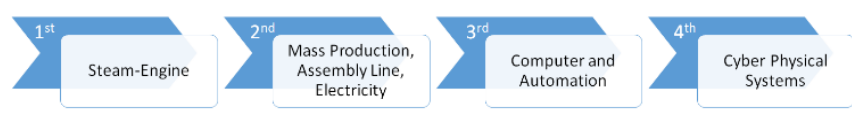

Fig. 1. Evolution of Manufacturing Systems

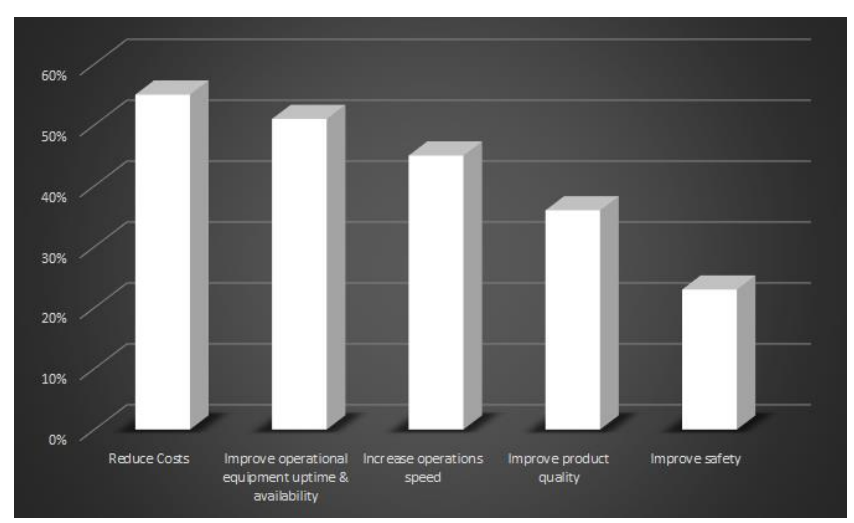

Fig. 2. Smart Manufacturing Benefits.

According to NIST [35] SMS is a "fully-integrated, collaborative manufacturing systems that respond in real time to meet changing demands and conditions in the factory, in the supply network, and in customer needs". Rockwell Automation defines SMS as "Smart Manufacturing is a highly connected, knowledge-enabled industrial enterprise where all business and operating actions are optimized to achieve substantially enhanced productivity, sustainability and economic performance".

A study made by Coalition (2011) reported the impact of SMS over a 10 years' time. Among the impacts, reduces safety incidents by $25 \%$, improving energy efficiency by $25 \%$, improves operating efficiency by $10 \%$, minimizes cycle times by $40 \%$, improves the lead-time by 10 times faster and increases revenue by $25 \%$. Fig. 2 shows the result that reveals the benefits of SMS as reported by Aberdeen [27],

SMS receives increasing attention in Malaysia in a seminar entitled "Government's Role in Industry 4.0" organized by the Ministry of International Trade and Industry (MITI) [28]. Six issues have been highlighted to enable the implementation of SMS in Malaysia, one of them is the lack of standards and technology. A task force has been formed to come up with a proposal that would mitigate these issues.

According to SME Corp Malaysia [29], smart manufacturing has multiple impacts as efficiency, productivity, return of investment, technology convergence, mega trends. To advance SMS, leading countries such as United States and Germany are focusing on related key technologies such as [3], [5]-[17]:

- Internet of Things (IoT) to collect real-time data and exchange it with other resources at real-time.

- Cyber-Physical Systems (CPS) to monitor or control a physical process via internet in a safe, reliable, efficient and real-time way using embedded computer and networks.

- Big data to process large and complex datasets using special algorithms. 
- Cloud computing to enable a full sharing and circulating of manufacturing resources.

- Sensor to share, exchange, and control data.

- Smart energy to monitor, analyse and optimise the consumption of the energy.

Meanwhile, SME Corp Malaysia [29] proposes nine pillars as key technologies to implement SMS as shown in Fig. 3.

However, focusing on the key technologies only would not mitigate the difficulties because few studies have discussed the configuration challenges prior to implementation while establishing new SMS [18]-[20]. Configuration involves identifying required machines, their quantities, and the workflow between machines, as well as the required technologies [19]. In addition, an evaluation for a selected configuration needs to be conducted prior to implementation too. The selection of a particular configuration and evaluation of the system prior to implementation mainly requires modeling and simulation study [21]-[23].

Wang et al. [30] propose a framework based cloudintegrated manufacturing to develop a self-organized smart factory. The framework incorporates wireless networks, cloud, big data analytics, and terminals such as machines, products, and conveyors to create intelligent automation production. Giret et al. [31] propose an approach for assisting serviceoriented Intelligent Manufacturing Systems (IMSs), which combine multi-agent with service-oriented architectures [64]. $\mathrm{Li}$ et al. [32] discuss the possible AI applications needed to develop IMS in China. Giret et al. [33] proposes a framework that assist the establishment of IMS by identifying the manufacturing components. Lee et al. [34] presents a cyberphysical system (CPS) architecture to provides practical guideline for the future SMS. Recent research by Nagadi et al. [19] propose a configuration framework using computer-based tools such as business process modelling and notation tool, agent-based modelling tool, expert systems, and discrete event simulation tool.

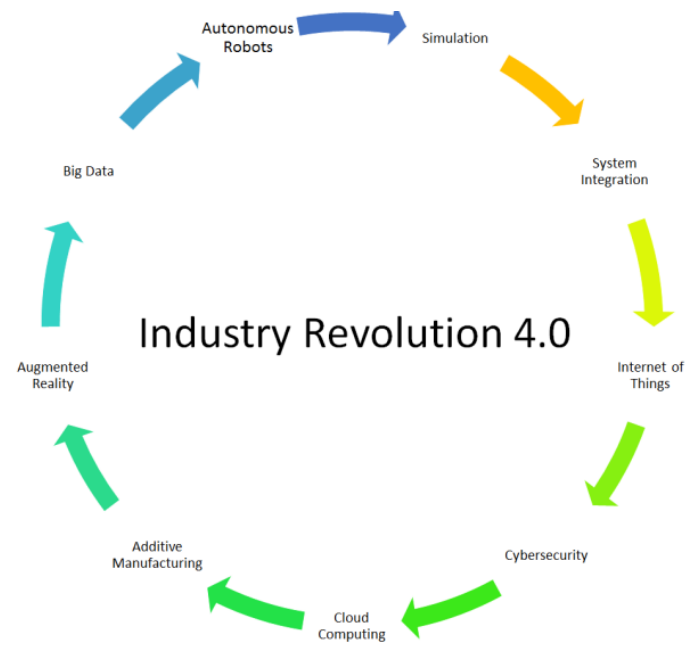

Fig. 3. Nine Pillars Proposed by SME Corp Malaysia.
However, very limited studies have been conducted on investigating and formulating the configuration factors, which can assist the industries' senior management in planning and establishing new SMS that minimize the operational cost and time, as well as improving efficient machine's utilization. To fill this gap, this study proposes to formulate a framework that generates SMS configurations. The proposed framework aids decision-makers in designing better SMS configurations and capabilities.

The proposed framework that is based on an application development that engages engineers throughout in a threephased, iterative process of application modelling; evaluation to ensure optimal configuration and adoption; and finally implementation.

As shown in Fig. 4, the modelling phase consists of Manufacturing System Components which are System Configuration; Functional Model; and Industrial Processes, and Smart Components which are Internet of Things (IoT); Cloud Computing; Big Data; Cyber-Physical System (CPS); and Agent-based Modelling (ABM). The evaluation phase consists of Simulation Model that includes Computer-based Simulation and Discrete Event Simulation (DES); finally, the implementation of the Smart Manufacturing System.

\section{A. Smart Manufacturing System Integration Model}

The modelling phase consists of two components, hardware and software. The hardware is represented by the manufacturing system components, while the software components are represented by the smart components. The combination of both constitutes the proposed Smart Manufacturing System Integration Model.

The manufacturing system components are System Configuration, Functional Model, and Industrial process. The System configuration specifies the type and numbers of required machines. The Functional Model presents the behavioral processes of a machine according to its functions while the industrial process determines the required interaction model among machines that reflects the production process flow.

The smart Components are Internet of Things (IoT) to establish communication between these machines/Agents; Cloud computing to enable a full sharing and circulating of manufacturing resources; Big Data to process large and complex datasets using special algorithms; Cyber-Physical System (CPS) to monitor or control the physical process via IoT and embedded algorithms. Agent-based Model (ABM) to model the behavior of the identified machines.

As shown in Fig. 5, the model firsts determines the configurations of the required system, then model the behavior of each component using ABM concept, and finally run and control the process via IoT, Cloud Computing, Big data, and CPS. The combination between the Manufacturing System Components and The Smart Components via agent-based Modeling constitutes the Smart Manufacturing System Integration model. 


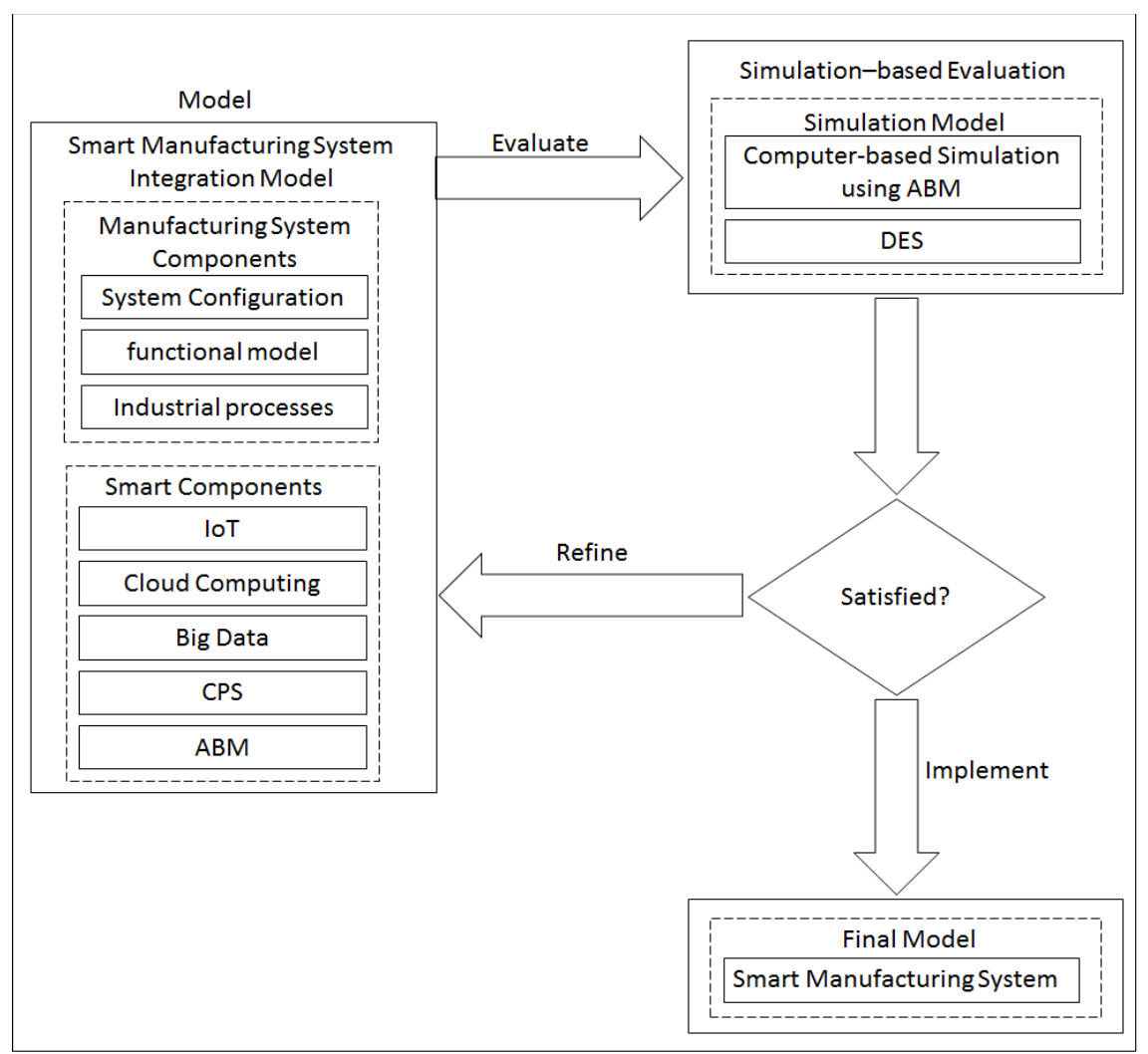

Fig. 4. Smart Manufacturing System Development Framework.

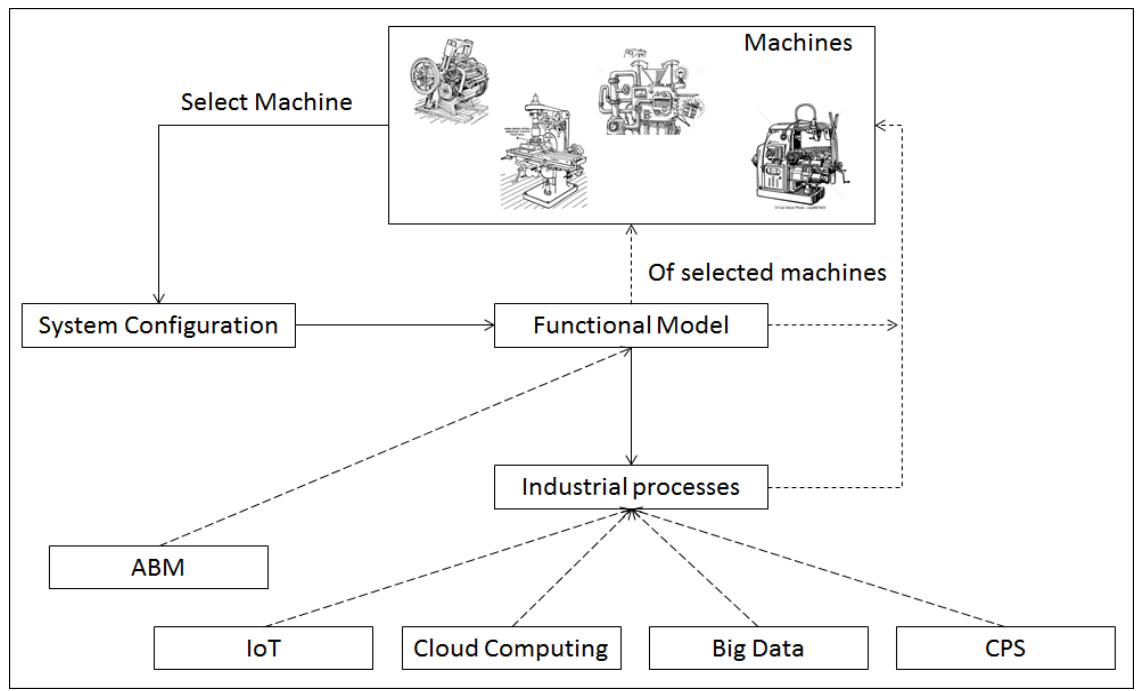

Fig. 5. Smart Manufacturing System Integration Model.

\section{B. Simulation-based Evaluation}

To simulate the system prior the implementation, two approached can be utilized for this purpose [19], Agent-based Modeling (ABM) to imitate a machine behavior and Discrete Event Simulation (DES) to mimic the industrial process flow as shown in Fig. 6.

The complete simulation strategy to evaluate a proposed system prior implementation is shown in Fig. 7. First software architects collaborate with manufacturing engineers to design the primary model. The manufacturing engineers specify the required type and number of machines and they describe the production process flow, in other words, the communication architecture between machines. Subsequently, software architects study the function and behavior of each machine to model its agent accordingly. Once all agents are modeled to represent the specified machines, software architects design the DES to mimic the described production process flow by the manufacturing engineers. The next step is evaluating the primary model via the simulation. 


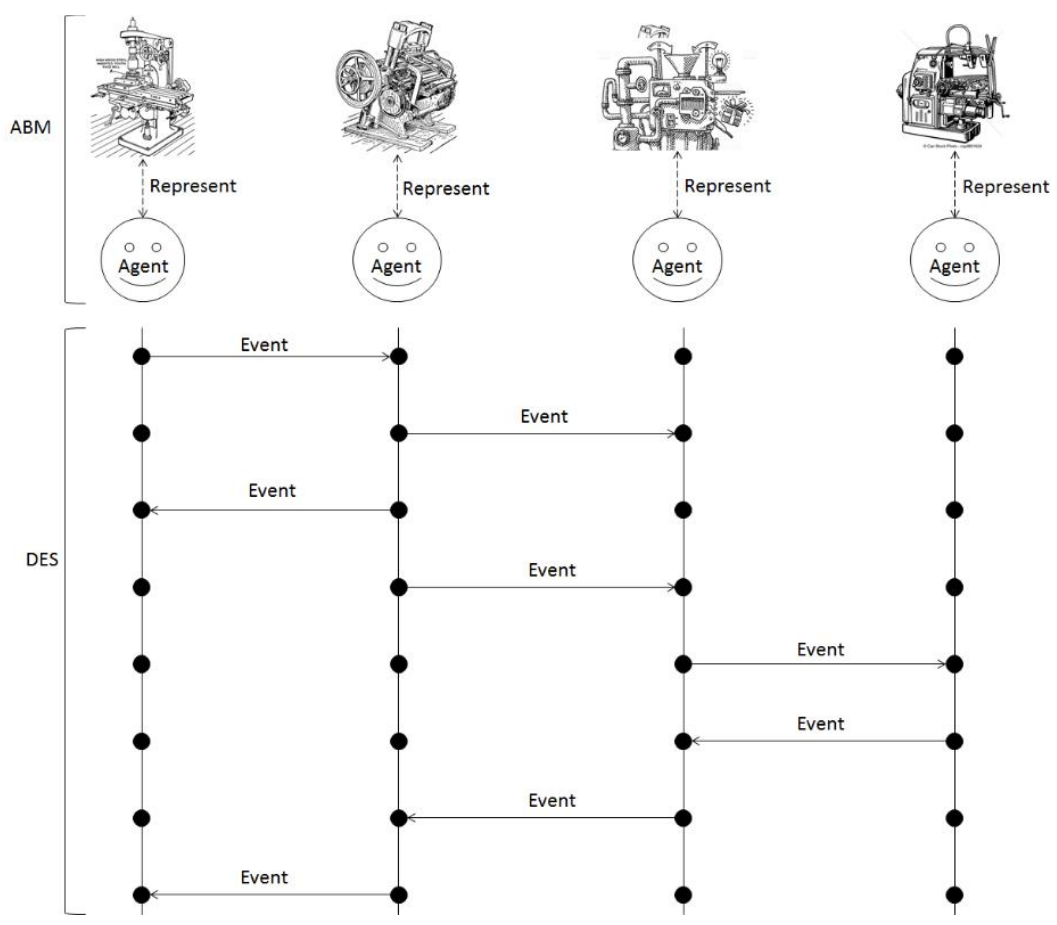

Fig. 6. Simulation Components.

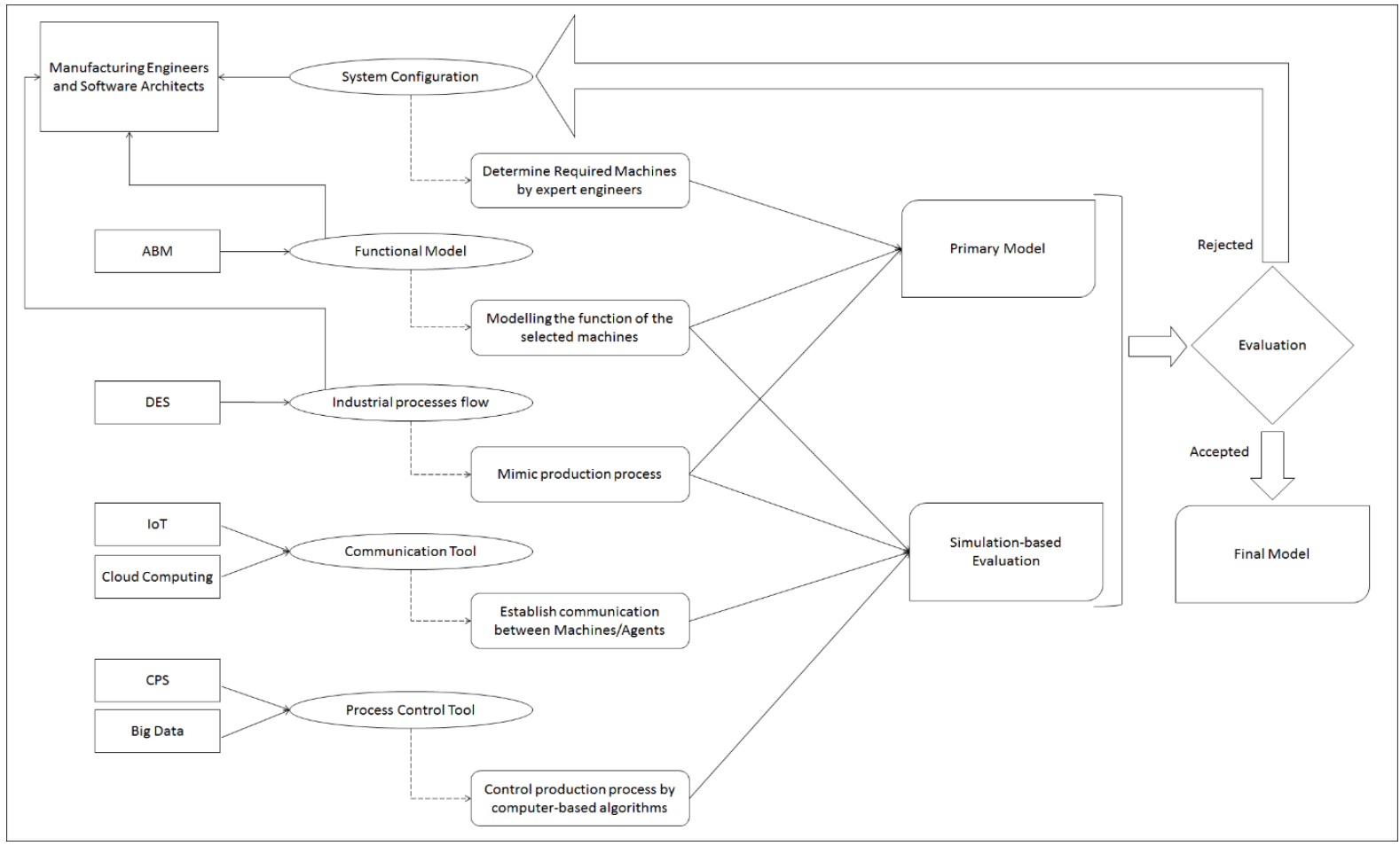

Fig. 7. Simulation-based Evaluation Model.

As shown in Fig. 4, the simulation components are ABM, DES, IoT, Cloud Computing, CPS, and Big Data. As mentioned earlier, ABM imitates machines functions and behavior and DES simulates production process flow. IoT and cloud computing provide a communication tools, IoT can provide agent to agent, or agent to cloud-cloud to agent. CPS is used to control the physical process via algorithms and network while the big data provide an effective mean to handle massive data accumulated overtime.

\section{Final Model}

The final model can be obtained after evaluating and subsequently refining the primary model. Several factors can be measured to evaluate the primary model such as applicability, efficiency, reliability, implementation cost, 
effectiveness, etc. If one or more factors are not within expectation, system re-configuration can be made by engineers and simulation-based evaluation can be applied again until all evaluation factors are in acceptable level.

\section{CONCLUSION}

The study of development framework in establishing new SMS is crucial for pre-implementation assessment that leads to minimized operational cost and time, as well as efficient machine's utilization. Thus, in this paper, we develop a framework that is based on an application development methodology that engages engineers throughout in a threephased, iterative process of application modelling; evaluation to ensure optimal configuration and adoption; and finally implementation. The modelling phase consists of Manufacturing System Components which are System Configuration; Functional Model; and Industrial Processes, and Smart Components which are Internet of Things (IoT); Cloud Computing; Big Data; Cyber-Physical System (CPS); and Agent-based Modelling (ABM). The evaluation phase consists of Simulation Model that includes Computer-based Simulation and Discrete Event Simulation (DES); finally, the implementation of the Smart Manufacturing System.

In our future work, we shall implement the developed framework to evaluate the primary model on different scenarios and subsequently produce the final model to ensure the quality, lead-time, and cost that optimize the usage of the capital investment and satisfy customers' requirements.

\section{ACKNOWLEDGMENT}

This project is sponsored by Universiti Tenaga Nasional (UNITEN) under the Internal Research Grant Scheme No. J510050835.

\section{REFERENCES}

[1] Zhong, R. Y., Xu, X., Klotz, E., \& Newman, S. T. (2017). Intelligent Manufacturing in the Context of Industry 4.0: A Review. Engineering, 3(5), 616-630.

[2] Report: Smart manufacturing market to hit $\$ 395.2$ billion by 2025 . https://www.techrepublic.com/article/report-smart-manufacturingmarket-to-hit-395-2-billion-by-2025/

[3] IM BizWatch September, 2017 http://iskandarmalaysia.com.my/wpcontent/uploads/2017/10/IM-BizWatch-September-2017.pdf

[4] Smart Manufacturing, The Way Forward for Malaysia, January 2017 http://www.mida.gov.my/home/3352/news/smart-manufacturing-theway-forward-for-malaysia/

[5] Kühnle, H., \& Bitsch, G.. Foundations \& principles of distributed manufacturing. Berlin: Springer, 2015, pp.55-70.

[6] Qu S, Jian R, Chu T, et al. Computational reasoning and learning for smart manufacturing under realistic conditions. In: Proceedings of the international conference on behavioral, economic, and socio-cultural computing, Shang.

[7] Park HS and Tran NH. Autonomy for smart manufacturing. J Korean Soc Precis Eng (2014); 31: 287-295.

[8] Rathinasabapathy R, Elsass MJ, Josephson JR, et al. A smart manufacturing methodology for real time chemical process diagnosis using causal link assessment. AIChE J 2016; 62: 3420-3431.

[9] Kibira D, Morris K and Kumaraguru S. Methods and tools for performance assurance of smart manufacturing systems. J Nat Inst Stand Technol 2015; 8099. Mittal et al. 17.

[10] Papazoglou MP, Van Den Heuvel WJ and Mascolo JE. Reference architecture and knowledge-based structures for smart manufacturing networks. IEEE Softw 2015; 32: 61-69.
[11] Lu Y, Morris KC and Frechette S. Standards landscape and directions for smart manufacturing systems. In: Proceedings of the IEEE international conference on automation science and engineering, Gothenburg, 24 August 2015, pp.998-1005. New York: IEEE.

[12] Davis J, Edgar T, Graybill R, et al. Smart manufacturing. Annu Rev Chem Biomol Eng 2015; 6: 141-160.

[13] Kulvatunyou B, Ivezic N, Morris KC, et al. Drilling down on smart manufacturing-enabling composable apps. Manuf Lett 2016; 10: 14-17.

[14] Shin SJ, Woo J and Rachuri S. Predictive analytics model for power consumption in manufacturing. Procedia CIRP 2014; 15: 153-158.

[15] Schabus S and Scholz J. Geographic Information Science and technology as key approach to unveil the potential of Industry 4.0: how location and time can support smart manufacturing. In: Proceedings of the 12th international conference on informatics in control, automation and robotics, Colmar, 21 July 2015, pp.463-470. New York: IEEE.

[16] Kusiak A. Smart manufacturing must embrace big data. Nature 2017; 544: 23-25.

[17] Shao G, Shin SJ and Jain S. Data analytics using simulation for smart manufacturing. In: Proceedings of the winter simulation conference, Savannah, GA, 7 December 2014, pp.2192-2203. New York: IEEE.

[18] Wang, S., Wan, J., Li, D., \& Zhang, C. (2016). Implementing smart factory of industrie 4.0: an outlook. International Journal of Distributed Sensor Networks, 12(1), 3159805.

[19] Nagadi, K., Rabelo, L., Basingab, M., Sarmiento, A. T., Jones, A., \& Rahal, A. (2018). A hybrid simulation-based assessment framework of smart manufacturing systems. International Journal of Computer Integrated Manufacturing, 31(2), 115-128.

[20] Giret, A., D. Trentesaux, M. A. Salido, E. Garcia, and E. Adam. 2017. "A Holonic Multi-Agent Methodology to Design Sustainable Intelligent Manufacturing Control Systems." Journal of Cleaner Production.

[21] Mittal, S., Khan, M. A., Romero, D., \& Wuest, T. (2017). Smart manufacturing: Characteristics, technologies and enabling factors. Proceedings of the Institution of Mechanical Engineers, Part B: Journal of Engineering Manufacture, 0954405417736547.

[22] Kang, H. S., Lee, J. Y., Choi, S., Kim, H., Park, J. H., Son, J. Y., ... \& Do Noh, S. (2016). Smart manufacturing: Past research, present findings, and future directions. International Journal of Precision Engineering and Manufacturing-Green Technology, 3(1), 111-128.

[23] Rizal Nainy Deputy CEO I SME Corp Malaysia 15 June 2017.

[24] Davidsson, P. (2002). Agent based social simulation: A computer science view. Journal of artificial societies and social simulation, 5(1).

[25] Gilbert, N. (2008). Agent-based models (No. 153). Sage.

[26] Nagadi, K. (2016). A framework to generate a smart manufacturing system configurations using agents and optimization.

[27] Greg Cline. Industry 4.0 and Industrial IoT in Manufacturing: A Sneak Peek, Aberdeen, Mar 31, 2017.

[28] MINISTRY OF INTERNATIONAL TRADE AND INDUSTRY, Industry 4.0 Seminar for Government Officials, June, 2017.

[29] SME Corp Malaysia, Industry 4.0 and its implications to SMEs, 15 June 2017.

[30] Wang, S., Wan, J., Li, D., \& Zhang, C. (2016). Implementing smart factory of industrie 4.0: an outlook. International Journal of Distributed Sensor Networks, 12(1), 3159805.

[31] Giret, A., E. Garcia, and V. Botti. 2016. "An Engineering Framework for Service-Oriented Intelligent Manufacturing Systems." Computers in Industry 81: 116-127.

[32] Li, B.-H., B.-C. Hou, W.-T. Yu, X.-B. Lu, and C.-W. Yang. 2017. "Applications of Artificial Intelligence in Intelligent Manufacturing: A Review." Frontiers of Information Technology \& Electronic Engineering 18 (1): 86-96.

[33] Giret, A., D. Trentesaux, M. A. Salido, E. Garcia, and E. Adam. 2017. "A Holonic Multi-Agent Methodology to Design Sustainable Intelligent Manufacturing Control Systems." Journal of Cleaner Production.

[34] Lee, J., B. Bagheri, and H.-A. Kao. 2015. "A Cyber-Physical Systems Architecture for Industry 4.0-Based Manufacturing Systems." Manufacturing Letters 3: 18-23. 
[35] The National Institute of Standards and Technology (NIST), https://www.nist.gov/

[36] Chan, F. T., et al. (2000). "The development of intelligent decision support tools to aid the design of flexible manufacturing systems." International Journal of Production Economics 65(1): 73-84.

[37] Karande, P. and S. Chakraborty (2013). "Evaluation and selection of flexible manufacturing systems using MACBETH method." International Journal of Services and Operations Management 16(1): 123-144.

[38] Maniya, K. and M. Bhatt (2011). "The selection of flexible manufacturing system using preference selection index method." International Journal of Industrial and Systems Engineering 9(3): 330349.

[39] Dallery, Y. and S. K. E. (1990). "On the Optimal Allocation of Servers and Workloads in Closed Queueing Networks." Operations Research 38(4): 694.

[40] Buzacott, J. A. and J. G. Shanthikumar (1992). "Design of manufacturing systems using queueing models." Queueing Systems 12(1-2): 135-213.

[41] Shen, W. and D. H. Norrie (1999). "Agent-based systems for intelligent manufacturing: a state-of-the-art survey." Knowledge and information systems 1(2): 129-156.

[42] Bülbül, H., et al. (2013). "An empirical investigation of advanced manufacturing technology investment patterns: Evidence from a developing country." Journal of Engineering and Technology Management 30(2): 136-156.

[43] Kang, H. S., et al. (2016). "Smart manufacturing: Past research, present findings, and future directions." International Journal of Precision Engineering and Manufacturing-Green Technology 3(1): 111-128.

[44] Radziwon, A., et al. (2014). "The Smart Factory: Exploring adaptive and flexible manufacturing solutions." Procedia Engineering 69: 1184-1190.

[45] Mahmoud, M. A., Ahmad, M. S., Yusoff, M. Z. M., \& Idrus, A. (2015). Automated multi-agent negotiation framework for the construction domain. In Distributed Computing and Artificial Intelligence, 12th International Conference (pp. 203-210). Springer, Cham.

[46] Mostafa, S. A., Gunasekaran, S. S., Ahmad, M. S., Ahmad, A., Annamalai, M., \& Mustapha, A. (2014, June). Defining tasks and actions complexity-levels via their deliberation intensity measures in the layered adjustable autonomy model. In Intelligent Environments (IE), 2014 International Conference on (pp. 52-55). IEEE.

[47] Mostafa, S. A., Ahmad, M. S., Tang, A. Y., Ahmad, A., Annamalai, M., \& Mustapha, A. (2014, April). Agent's autonomy adjustment via situation awareness. In Asian Conference on Intelligent Information and Database Systems(pp. 443-453). Springer, Cham.

[48] Mahmoud, M. A., Ahmad, M. S., \& Yusoff, M. Z. M. (2016, March). A norm assimilation approach for multi-agent systems in heterogeneous communities. In Asian Conference on Intelligent Information and Database Systems (pp. 354-363). Springer, Berlin, Heidelberg.

[49] Mahmoud, M., Ahmad, M. S., \& Yusoff, M. Z. M. (2016). Development and implementation of a technique for norms-adaptable agents in open multi-agent communities. Journal of Systems Science and Complexity, 29(6), 1519-1537.

[50] Subramainan, L., Mahmoud, M. A., Ahmad, M. S., \& Yusoff, M. Z. M. (2017, June). A Simulator's Specifications for Studying Students' Engagement in a Classroom. In International Symposium on Distributed Computing and Artificial Intelligence (pp. 206-214). Springer, Cham.

[51] Mostafa, S. A., Ahmad, M. S., Annamalai, M., Ahmad, A., \& Gunasekaran, S. S. (2015). Formulating dynamic agents' operational state via situation awareness assessment. In Advances in Intelligent Informatics (pp. 545-556). Springer, Cham.

[52] Mostafa SA, Ahmad MS, Annamalai M, Ahmad A, Gunasekaran SS. A dynamically adjustable autonomic agent framework. InAdvances in Information Systems and Technologies 2013 (pp. 631-642). Springer, Berlin, Heidelberg.

[53] Mostafa SA, Darman R, Khaleefah SH, Mustapha A, Abdullah N, Hafit H. A General Framework for Formulating Adjustable Autonomy of Multi-agent Systems by Fuzzy Logic. InKES International Symposium on Agent and Multi-Agent Systems: Technologies and Applications 2018 Jun 20 (pp. 23-33). Springer, Cham.

[54] Ahmed, M., Ahmad, M. S., \& Yusoff, M. Z. M. (2010, November). Modeling agent-based collaborative process. In International Conference on Computational Collective Intelligence (pp. 296-305). Springer, Berlin, Heidelberg.

[55] Mahmoud, M. A., Mustapha, A., Ahmad, M. S., Ahmad, A., Yusoff, M. Z. M., \& Hamid, N. H. A. (2013). Potential norms detection in social agent societies. In Distributed Computing and Artificial Intelligence (pp. 419-428). Springer, Cham.

[56] Subramainan, L., Yusoff, M. Z. M., \& Mahmoud, M. A. (2015, August). A classification of emotions study in software agent and robotics applications research. In 2015 International Symposium on Agents, Multi-Agent Systems and Robotics (ISAMSR) (pp. 41-46). IEEE.

[57] Mahmoud, M. A., \& Ahmad, M. S. (2015, August). A self-adaptive customer-oriented framework for intelligent strategic marketing: A multi-agent system approach to website development for learning institutions. In 2015 International Symposium on Agents, Multi-Agent Systems and Robotics (ISAMSR) (pp. 1-5). IEEE.

[58] Ahmed, M., Ahmad, M. S., \& Yusoff, M. Z. M. (2010, June). Mitigating human-human collaboration problems using software agents. In KES International Symposium on Agent and Multi-Agent Systems: Technologies and Applications (pp. 203-212). Springer, Berlin, Heidelberg.. 